\title{
Extreme polymorphism in a Y-linked sexually selected trait
}

\author{
AK Lindholm ${ }^{1,2}$, R Brooks ${ }^{2}$ and F Breden ${ }^{1}$ \\ ${ }^{1}$ Behavioural Ecology Research Group, Department of Biological Sciences, Simon Fraser University, Burnaby, BC, Canada V5A 1S6; \\ ${ }^{2}$ School of Biological, Earth and Environmental Sciences, University of New South Wales, Sydney NSW 2052, Australia
}

\begin{abstract}
Males of the livebearing fish, Poecilia parae, exhibit one of the most complex polymorphisms known to occur within populations, whereas females are monomorphic. We describe five distinct male colour morphs and an associated size dimorphism, and demonstrate through pedigree analysis that the locus or loci controlling the male colour polymorphism is linked to the Y-chromosome. Field surveys from 1999 to 2002 of nine populations in Guyana and Suriname, South America, indicate that some morphs are consistently abundant and others are rare, implying that the colour polymorphism has important fitness consequences. By rearing offspring of field-inseminated females, we showed
\end{abstract}

that the common morph is also the most successful morph in terms of reproduction. However, dichotomous choice tests show that two rare morphs are preferred by females over the common morph. These results suggest that alternative male mating strategies, sperm competition, overt male-male competition, or other processes are overriding female preferences in these populations. Furthermore, Y-linkage of the colour polymorphism in $P$. parae supports the hypothesis that heterogametic sex chromosomes harbour sexually antagonistic traits beneficial to the heterogametic sex.

Heredity (2004) 92, 156-162, advance online publication, 21 January 2004; doi:10.1038/sj.hdy.6800386

Keywords: genetic polymorphism; Y-chromosome; Poecilia parae; sexual selection

\section{Introduction}

Understanding the maintenance of variation that occurs in discrete morphs is a classic question in evolutionary genetics (eg Fisher, 1931; Clarke, 1962). Several basic questions must be answered in order to understand the maintenance of such polymorphisms. To what extent are they environmentally or genetically controlled? If genetically controlled, what are the detailed genetic mechanisms underlying the variation (eg, number of loci, linkage patterns)? What are the temporal and spatial distributions of morphs? And what are the fitness consequences of the different types?

Models of sexual selection (eg Lande, 1981; Rice, 1984) and reproductive isolation (eg Kondrashov and Kondrashov, 1999) have shown the importance of understanding the genetic basis of characters involved in these processes, and therefore there has been much recent interest in the genetic architecture of sexually selected traits (eg Reinhold, 1998; Ritchie and Phillips, 1998; Lande and Wilkinson, 1999; Sinervo and Svensson, 2002). For example, linkage patterns may facilitate or constrain genetic correlations underlying sexual selection processes (Lande and Wilkinson, 1999; Lindholm and Breden, 2002). Furthermore, fitness consequences such as those due to sexual selection can influence the linkage patterns themselves. Sexually antagonistic traits, those that are beneficial to one sex but detrimental to the other,

Correspondence: A Lindholm, School of Biological, Earth and Environmental Sciences, University of New South Wales, Sydney NSW 2052, Australia. E-mail: anna.lindholm@unsw.edu.au

Received 13 January 2003; accepted 10 June 2003 are often inherited on sex chromosomes rather than autosomes (Reinhold, 1998). Sexually antagonistic traits that benefit the heterogametic sex are thought to evolve more easily when linked to the heterogametic sex chromosome ( $\mathrm{Y}$ or $\mathrm{W}$ ), as they are not subject to selection in the other sex (Fisher, 1931; Rice, 1987). Thus, determining the genetic basis and linkage patterns of sexually selected traits is essential to understanding their evolution.

Here, we present the first detailed study of the inheritance and geographic distribution of a sex-limited discrete polymorphism in colour and size in males of the livebearing fish Poecilia parae. The morphs are sufficiently distinct that two of them were originally named as separate species: P. vivipara parae (Eigenmann, 1894) and Acanthophacelus melanzonus (Eigenmann, 1909). They were later classified as one species, $P$. parae, with three male morphs: parae, melanzona and the uncoloured immaculata (Rosen and Bailey, 1963). Within the melanzona morph, blue and red variants have previously been noted from Guyana (Liley, 1963) and blue and yellow variants from French Guiana (Keith et al, 2000).

We document five male morphs in P. parae and show that all five morphs can occur within a single population. We use field surveys to show that distribution patterns within and between populations suggest strong fitness effects. We then show that these morphs are probably under sexual selection by measuring variation in mating success in the wild, and the discrimination of males by females on the basis of colour in the laboratory. Finally, we use pedigree analyses to determine the genetic basis and linkage pattern of male colour morphs. 


\section{Methods}

\section{Field surveys}

P. parae occurs along the coast from Guyana to the mouth of the Amazon River in Brazil (Rosen and Bailey, 1963). To document the frequency of morphs and their geographic distribution, we searched for $P$. parae near the coast in ditches draining into rivers in Guyana and Suriname in four separate sets of field surveys (Guyana: June-August 1999, November 2000, January-February 2002; Suriname: May 2000). P. parae were only found in mud-bottomed ditches of a variety of sizes that served as sewerage outlets. We considered different drainage systems into a river as different sampling sites. Adult males and females were captured with dip nets or a $3 \mathrm{~m} \times 1.5 \mathrm{~m}$ seine net, and male colour patterns were scored. We noted potential predators, based on Winemiller et al (1990) and Endler (1978). At the end of each sampling period, fish were either released or taken into captivity.

\section{Variation in morph mating success and investigation of genetic basis of colour morphs}

Male and female $P$. parae were transported to Simon Fraser University, Canada from Georgetown, Guyana in 1999 and from Suriname in 2000. To determine the distribution of morphs among offspring of females that had mated in the wild, we isolated females in 51 tanks for 3-5 months to allow them to produce offspring from field inseminations (poeciliids can store sperm for several months; Constantz, 1989). Surviving females were then assigned a mate. All offspring in a brood were transferred to a new tank after birth. Prior to sexual maturity (full gonopodial development), sons were separated from daughters to prevent uncontrolled inseminations. Male phenotypes were scored when colours developed, upon sexual maturity. Males were scored as 'immaculata' if they did not develop colour 2 months after sexual maturity. In no case did males initially scored as immaculata later develop colour. All fish were kept on a natural daylight schedule and fed with TetraMin fish flakes and brine shrimp nauplii.
To determine the genetic basis and linkage pattern of loci underlying colour morphs, we analysed pedigrees of males and females from Georgetown and their descendants. We assigned mates to virgin daughters and isolated and reared resulting offspring as above.

\section{Dichotomous mate choice tests}

Dichotomous choice tests were conducted in one of two identical glass aquaria in the morning from 22 June to 30 August 1999 in Georgetown at the laboratory of the guesthouse of the Smithsonian Research Institute. Each aquarium had four compartments: a central compartment $\left(23 \times 30 \mathrm{~cm}^{2}\right)$ and two end compartments $\left(11 \times 30 \mathrm{~cm}^{2}\right)$, one of which was divided to make two equal sized compartments $\left(11 \times 15 \mathrm{~cm}^{2}\right)$, one for each test male. The test female in the middle compartment was able to see both males at one end of the aquarium at the same time. At the compartment at the other end of the tank were two companion females who were housed there for days at a time and provided the test female an opportunity to school with other females rather than with only males. Males did not direct courtship towards these females.

Each aquarium contained 201 of rainwater to a depth of $21 \mathrm{~cm}$, and a tablespoon of sea salt. Rainwater was used to provide standard experimental conditions, as the colour of water collected from the field sites varied between days and between study sites. A layer of tan gravel lined the bottom of the tanks. Differences in the background exterior to the tanks were minimized by covering the glass with translucent waxed paper, except for the glass of the companion female compartment, through which the behaviour of the test female and males was observed. Lighting was provided by natural daylight and an Aquari-lux FL-20 full-spectrum aquarium light suspended $37 \mathrm{~cm}$ above the water surface and centred between the two tanks, which were placed $11 \mathrm{~cm}$ apart.

At the start of a choice test, a test female, a parae male and an equal-sized (within $1 \mathrm{~mm}$ in standard length) opponent male were placed into their respective compartments (see Figure 1 for photographs of males). The parae male was placed into the right compartment (with
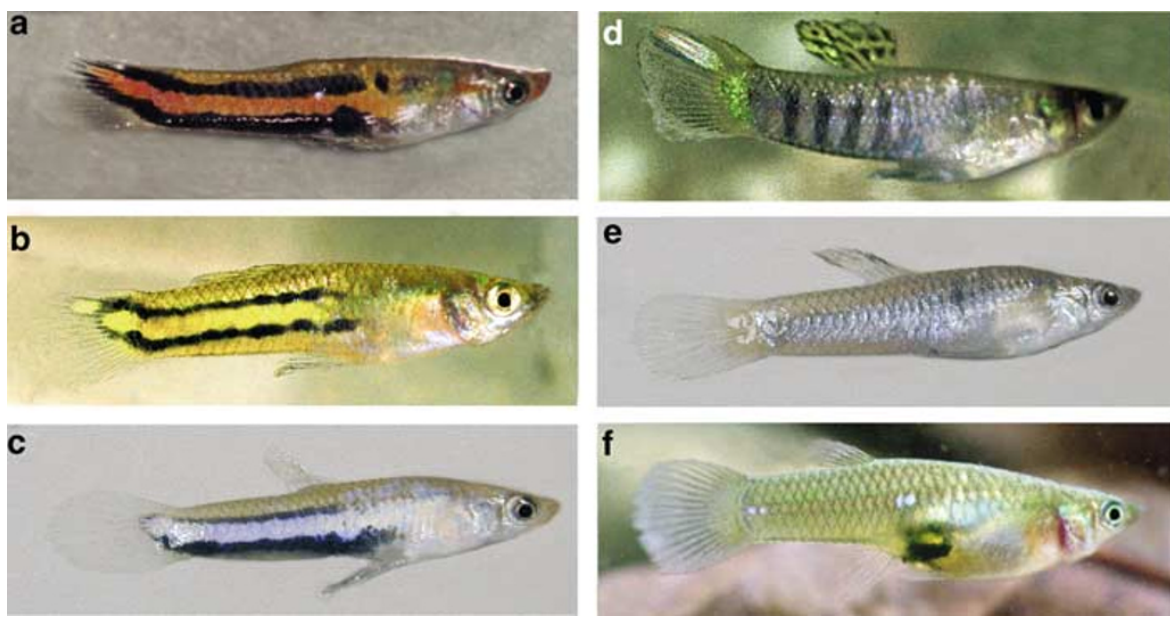

Figure 1 Male and female Poecilia parae from Guyana: (a) red melanzona, (b) yellow melanzona, (c) blue melanzona, (d) parae, (e) immaculata and (f) female. The immaculata male was photographed 12 months after capture as a sexually mature male. 
respect to the observer) in half of the trials. Opaque and clear glass partitions divided the two male compartments, and also the male compartments and the test female compartment. After an acclimation period of $10 \mathrm{~min}$, the opaque partitions were removed, and the behaviour of males and the female observed for $10 \mathrm{~min}$. Removal of the opaque partition between males was important because it allowed the males to see each other, which increased male courtship (as in guppies $P$. reticulata; Farr, 1976). The opaque partitions were then replaced, and the males were switched between compartments. After another acclimation period, the opaque partitions were again removed and the fish were observed for an additional $10 \mathrm{~min}$. The second observation period controlled for any side preferences of the female.

Fish behaviours were measured by the observer (AL) seated approximately $0.5 \mathrm{~m}$ away from the end of the tank housing the companion females. A computer with an event recorder program written by FB was used to record the number of seconds that the test female spent orientated toward each male against the glass of his compartment. The duration of attentiveness (defined as orientation to the female) was measured for each male. We also measured the numbers of dart displays, which were defined as extremely rapid movements to and fro (Liley, 1966). Dart-displays are the most common male display to precede copulation attempts in P. parae (Liley, 1966). Trials were considered successful if the female was orientated towards at least one male in each of the two observation periods, if the female swam calmly in the tank, and if both males showed interest in the female. Females and males from a successful trial were not used again. In total, 97 trials were conducted, of which 56 were successful. Of 56 females, 32 were tested within $48 \mathrm{~h}$ of parturition, 13 were tested later in the reproductive cycle and the remaining 11 females did not give birth in the laboratory. These trials tested female preference between 56 different parae males paired with 47 melanzona and nine immaculata males.

\section{Results}

\section{Five male morphs}

The five male morphs are shown in Figure 1. Three morphs, the yellow, red and blue, are of the melanzona type, with double horizontal black stripes along the length of the body. For simplicity, these morphs will be called hereafter the yellow, red and blue morphs. The parae morph has a colourful tail stripe and vertical bars which are facultatively expressed. The fifth morph, the immaculata, lacks stripes and thus has juvenile colouration. This colouration is developmentally stable -13 wild-caught sexually mature immaculata did not alter colour pattern during 6 months of captivity (see also the caption of Figure 1). The morphs varied in standard length (Table 1), as immaculata males were significantly smaller than the other four types (Tukey test, all comparisons with immaculata males $P<0.05$, all others not significant).

\section{Field surveys}

The parae morph was more abundant than red, blue or yellow males at all nine sites and in all years (Table 2),
Table 1 Standard length of male morphs plus ANOVA test statistic

\begin{tabular}{lrrrrrr}
\hline Morph & N & \multicolumn{2}{c}{ Standard length } & $F$ & $d f$ & $\mathrm{P}$ \\
\cline { 3 - 4 } & & Mean & SD & & & \\
\hline Parae & 200 & 19.2 & 1.4 & 13.80 & 4332 & 0.001 \\
Blue & 37 & 18.9 & 1.2 & & & \\
Red & 37 & 19.1 & 1.1 & & & \\
Yellow & 30 & 18.4 & 1.4 & & & \\
Immaculata & 33 & 17.4 & 1.1 & & & \\
\hline
\end{tabular}

including samples from 1954 and 1956 (Liley, 1963). In $11 / 12$ surveys, blue was next most abundant, leaving red and yellow as the least abundant morphs. Within this broad trend, there was significant heterogeneity in morph frequencies between years at one of two sites that were surveyed twice (Demerara West $3(\mathrm{G}=11.79$, $\mathrm{df}=2, P<0.005)$ vs Demerara East $1(\mathrm{G}=5.05, \mathrm{df}=3$, $P>0.1)$, and across all sites $(\mathrm{G}=53.29, \mathrm{df}=24, P<0.001$, using the largest survey at Demerara West 3 and Demerara East 1). Notably, at four sites red males were not detected. We tested whether the distribution of morph frequencies varied geographically using a Mantel test. For sites that had been surveyed more than once, we used only the largest survey. There was no correlation $(r=0.008, P=0.33)$ between the matrix of geographical coordinates of sampling sites and the matrix of frequencies of parae, red, blue and yellow males. Thus, we found no evidence of a systematic effect of geographical location on morph frequencies.

We could not include data for immaculata males, as these males could not be distinguished in the field from nearly mature juveniles of other morphs, which had yet to develop colour. Thus, the frequency of uncoloured males scored in 2002 surveys overestimated the frequencies of immaculata, as some uncoloured males are immature parae, red, blue or yellow males. These data do however place an upper boundary on estimates of immaculata frequency for these samples, at up to $53.4 \%$ (Table 2) of all sexually mature males.

The predator communities probably varied among sites. At Demerara River West sites 3 and 4, water depth was shallow, ranging from $5-40 \mathrm{~cm}$ and the only potential predators observed were Hemigrammus spp. (up to $7 \mathrm{~cm}$ long) and Rivulus spp. (up to $5.5 \mathrm{~cm}$ long). At all sites on the East bank of the Demerara River, and site 2 on the West Bank, trenches were larger and water depth was up to $1.5 \mathrm{~m}$. These were local fishing sites for the cichlids Oreochromis mossambicus and Crenicichla spp.

\section{Variation in morph mating success}

Nine wild-caught females from Georgetown and six from Suriname produced sons in the laboratory in Canada from field inseminations. Eight of the nine females from Georgetown produced only parae sons $(N=19)$, while one produced both parae $(N=4)$ and immaculata sons $(N=6)$. The six females from Suriname produced only parae sons $(N=8)$. As a conservative test of the hypothesis that parae males have higher mating success relative to their frequency in the population (relative to the melanzona morphs), we compared the observed frequencies of parae litters with an expectation based on a proportion of $69 \%$ (this proportion is the 
Table 2 Counts of colour morphs by site and year

\begin{tabular}{|c|c|c|c|c|c|c|c|c|c|c|c|c|}
\hline \multirow[t]{2}{*}{ Site } & \multicolumn{2}{|c|}{ Coordinates } & \multirow[t]{2}{*}{ Sampling year } & \multicolumn{2}{|c|}{ Parae } & \multicolumn{2}{|c|}{ Blue } & \multicolumn{2}{|c|}{ Yellow } & \multicolumn{2}{|c|}{ Red } & \multirow{2}{*}{$\frac{\text { Uncoloured }}{\mathrm{N}}$} \\
\hline & $\mathrm{N}$ & W & & $\mathrm{N}$ & $(\%)$ & $\mathrm{N}$ & $(\%)$ & $\mathrm{N}$ & $(\%)$ & $\mathrm{N}$ & $(\%)$ & \\
\hline \multirow[t]{2}{*}{ Demerara R. East 1} & $6^{\circ} 49.427$ & $58^{\circ} 09.550$ & 1999 & 200 & $(69.0)$ & 41 & (14.1) & 23 & $(8.0)$ & 26 & $(8.9)$ & \\
\hline & & & 2000 & 27 & (84.3) & 1 & $(3.1)$ & 2 & $(6.3)$ & 2 & $(6.3)$ & \\
\hline \multirow[t]{3}{*}{ Demerara R. East 2} & $6^{\circ} 48.315$ & $58^{\circ} 09.076$ & 1999 & 36 & (61.0) & 15 & $(25.4)$ & 6 & $(10.2)$ & 2 & $(3.4)$ & \\
\hline & & & $1954^{\mathrm{a}}$ & 5 & $(55.6)$ & & & & & & & \\
\hline & & & $1956^{\mathrm{a}}$ & 7 & $(53.8)$ & & & & & & & \\
\hline Demerara R. East 3 & $6^{\circ} 48.036$ & $58^{\circ} 09.069$ & 2002 & 112 & $(43.6)$ & 83 & (32.3) & 17 & $(6.6)$ & 45 & (17.5) & 102 \\
\hline Demerara R. West 1 & $6^{\circ} 47.797$ & $58^{\circ} 11.112$ & 2002 & 111 & (66.9) & 30 & (18.1) & 5 & $(3.0)$ & 20 & (12.0) & 136 \\
\hline Demerara R. West 2 & $6^{\circ} 47.148$ & $58^{\circ} 11.497$ & 2002 & 33 & $(60.0)$ & 18 & (30.5) & 8 & (13.5) & 0 & (0) & 20 \\
\hline \multirow[t]{2}{*}{ Demerara R. West 3} & $6^{\circ} 42.722$ & $58^{\circ} 12.452$ & 2000 & 77 & (93.9) & 4 & $(4.9)$ & 1 & $(1.2)$ & 0 & (0) & \\
\hline & & & 2002 & 101 & $(77.1)$ & 22 & (16.8) & 8 & (6.1) & 0 & (0) & 150 \\
\hline Demerara R. West 4 & $6^{\circ} 41.472$ & $58^{\circ} 11.858$ & 2002 & 714 & $(70.0)$ & 234 & $(22.9)$ & 66 & $(6.5)$ & 6 & $(0.6)$ & 915 \\
\hline Berbice R. West & $6^{\circ} 16.347$ & $58^{\circ} 32.511$ & 2002 & 108 & $(74.0)$ & 26 & (17.8) & 12 & $(8.2)$ & 0 & $(0)$ & 155 \\
\hline Suriname R. East & $6^{\circ} 53.075$ & $58^{\circ} 05.375$ & 2000 & 27 & (56.3) & 11 & $(22.9)$ & 10 & (20.8) & 0 & (0) & \\
\hline
\end{tabular}

aData from Liley (1963), who compared the frequency of parae $v$ s all melanzona males.

Percentage composition of parae, blue, yellow and red in 2002 was calculated without the inclusion of uncoloured males to facilitate comparisons with surveys from earlier years.

highest of the three proportions of parae:melanzona males in the sites from which these females were collected - Demerara East 1 and 2, and Suriname River West). Parae males had significantly higher mating success than expected from their proportion of 0.69 in the population $\left(\mathrm{G}_{1}=11.11, P=0.001\right)$.

\section{Inheritance of colour morphs}

Controlled matings showed a simple genetic basis to the colour morphs. In 14/14 cases, laboratory-reared females that were mated as virgins bore sons displaying the paternal phenotype (Table 3 ). The exact probability that all 23 sons matched their paternal phenotype by chance alone is $(1 / 5)^{23}$. Further evidence of paternal inheritance comes from females that produced sons of different phenotypes following remating. Three field-inseminated females that had parae sons in the laboratory were later remated to a red, blue or yellow male. These females subsequently produced no more parae sons, but sons that matched the morph of the male used in the remating. Another female had immaculata sons followed by a brood of red sons, after remating to a red male. These patterns of inheritance suggest that the alleles determining male colour patterns are linked to the Ychromosome.

Pedigrees for descendants of three wild-caught females (including two of the four remated females just discussed) further show that colour patterns are inherited through the sire (Figure 2), with no apparent influence of maternal genotype. The pedigree of the descendants of female A rules out X-linkage of the alleles for colour. One obvious autosomal model, assuming that the parae morph is recessive, can be rejected at $P<0.05$ (this model is explained in the caption to Figure 2). Thus, the pattern of inheritance is completely consistent with linkage to the Y-chromosome, but inconsistent with Xchromosome or autosomal linkage of colour-determining alleles.

\section{Female discrimination of colour morphs}

As the parae morph was most successful in terms of frequency in the wild and in mating success, we
Table 3 Offspring phenotype vs paternal phenotype from 14 crosses, scored per female with total number of sons produced in parentheses

\begin{tabular}{|c|c|c|c|c|}
\hline \multirow[t]{2}{*}{ Son's phenotype } & \multicolumn{4}{|c|}{ Paternal phenotype } \\
\hline & Red & Yellow & Parae & Immaculata \\
\hline Red & $4(7)$ & & & \\
\hline Yellow & & $2(4)$ & & \\
\hline Parae & & & $6(8)$ & \\
\hline Immaculata & & & & $2(4)$ \\
\hline
\end{tabular}

${ }^{a}$ No blue males produced mature male progeny in this experiment.

hypothesized that females would prefer the parae morph to all others. Thus, we designed female choice tests to compare female preferences for the parae morph against each of the other morphs, while controlling for differences in body size. Females spent less time with parae than with yellow males in 11/13 trials and less time with parae than red males in 15/21 trials (binomial tests, onetailed, $P<0.04)$. Immaculata were less attractive than equal-sized parae males, as females spent more time with parae than immaculata in 8/9 trials (binomial test, one-tailed, $P<0.02$ ). Blue melanzona males were preferred to parae males in 6/13 trials (binomial test, onetailed, $P=0.71$ ). It is not clear, however, that females showed no preference, as the power of the test was low (power $=0.27$ for $N=13$, effect size $=0.25$, alpha $=0.05$, one-tailed).

We tested if males differed in their courtship behaviour, as this might influence female preferences. However, male colour morphs did not differ in their courtship behaviour during trials. Immaculata, parae, red, yellow and blue males performed similarly in terms of attentiveness time and number of darts performed (Table 4).

\section{Discussion}

$P$. parae has five distinct male-specific morphs that differ in colour pattern and body size. Male colour morphs have a genetic basis that is consistent with a simple model of five alternative Y-linked alleles. In well-studied 
systems of male-limited colour morphs, allelomorphs underlie variation in male colour pattern (Angus, 1989; Shuster and Wade, 1991; Sinervo, 2001; Lindholm and Breden, 2002), which is consistent with our results. In livebearing fishes (Poeciliidae), 12 species other than $P$. parae have Y-linked alleles that cause variation in male colour or body size (Lindholm and Breden, 2002). In contrast to mammals, Y-chromosomes are typically not highly degenerate in poeciliids, which presumably facilitates Y-linkage of functional genes.

We have demonstrated that the parae morph is by far the most abundant morph at all sites sampled and over time periods greater than 40 years, and that parae males enjoy greater mating success in the wild than would be

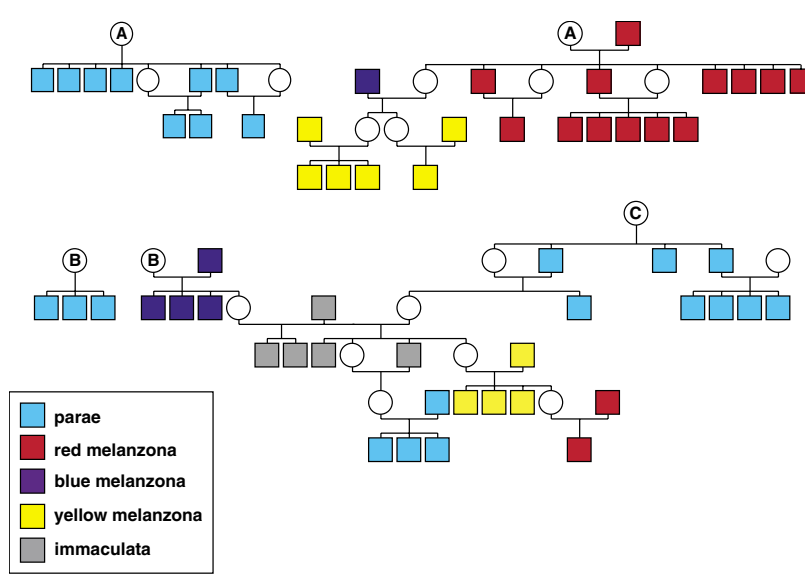

Figure 2 Pedigrees for offspring of wild-caught females A, B and C. All three produced offspring from field inseminations, but $A$ and $B$ were later remated to males of known phenotype, and are therefore represented twice. Daughters that produced no male descendants were omitted. This pedigree can be used to reject $X$-linkage: under the X-linked model, female A must have X-linked alleles for the parae and red morphs. Her daughter mated to the blue morph would therefore have no X-linked alleles for the yellow morph, and yet she produces yellow males. This pedigree can also be used to calculate exact probabilities for the autosomal model, under various dominance relations among the alleles and assumptions about population gene and genotype frequencies. One obvious model would be to assume that the parae morph is recessive to all other morphs, thus making the change from parae male offspring to male offspring with the new father's phenotype most likely. Assuming that unknown genotypes are homozygous for the autosomal parae allele (this morph has the highest frequency in all natural populations) and that each female is an independent test of the autosomal model (ie, using Fisher's combined probabilities test over all females; Sokal and Rohlf, 1969), the probability of perfect association between paternal phenotype and male offspring phenotype is less than 0.05 . expected based on their frequency in the population. Furthermore, we have shown that females can discriminate between males of different morphs in a way that is consistent with mate choice. Thus, there appear to be strong fitness effects associated with colour morph, and colour morphs are likely to be under sexual selection.

The high mating success of parae males might reflect a female preference for mating with males of that morph. However, dichotomous choice tests provide no evidence for this and instead indicate that females discriminate against parae in favour of yellow and red males. Another study of preference in this species has also observed that the yellow and red melanzona morphs are preferred by females in choice tests (Bourne et al, 2003). In our present study, females only preferred to associate with parae when given a choice between parae and the uncoloured immaculata. These results suggest that the high mating success achieved by parae is not simply due to female choice, but may be due to other sexually selected advantages such as superior ability in overt male-male contests, in sperm competition, or in obtaining sneaky copulations. There is as yet no evidence for this, as we found no differences in male courtship behaviour between morphs in our female choice tests. However, Magurran (1998) has argued that such male-driven factors can overcome female preference in the guppy, which is closely-related to P. parae (Breden et al, 1999).

Female preferences for associating with red and yellow males suggest that negative frequency-dependent female mate choice is a possible mechanism for the maintenance of these rarer morphs. Female side-blotched lizards Uta stansburiana maximise their fitness by mating with rare males in low-density years (Alonzo and Sinervo, 2001). In the guppy, rare or novel males enjoy a mating advantage (Farr, 1977; Hughes et al, 1999). As yet, we have no evidence of differential mating success in favour of red and yellow males in $P$. parae. Other selective pressures and processes might act in the opposite direction, to reduce the frequency of these rare but brightly coloured morphs. They may experience higher rates of predation, as is believed to be the case in guppies (Haskins et al, 1961; Endler, 1983; Godin and McDonough, 2003). Differential predation might therefore reduce the numbers of red and yellow males relative to parae and immaculata males. Although we did not measure predation rates, we found the highest frequencies of red males in large ditches supporting large predatory fish, suggesting that there is not a simple relationship between predation risk and relative frequency of brightly coloured males.

Table 4 Comparison of male courtship

\begin{tabular}{|c|c|c|c|c|c|c|c|c|c|c|c|}
\hline \multirow[t]{2}{*}{ Morph } & \multirow[t]{2}{*}{$\mathrm{N}$} & \multicolumn{5}{|c|}{ Attentiveness (s) } & \multicolumn{5}{|c|}{ Dart displays } \\
\hline & & Mean & $S D$ & $\chi^{2}$ & $d f$ & $\mathrm{~Pa}$ & Mean & $S D$ & $\chi^{2}$ & $d f$ & $\mathrm{~Pa}$ \\
\hline Parae & 56 & 801.6 & 298.4 & 3.65 & 4 & 0.46 & 0.85 & 2.55 & 3.96 & 4 & 0.41 \\
\hline Blue & 13 & 916.8 & 336.8 & & & & 1.15 & 2.27 & & & \\
\hline Red & 21 & 787.5 & 301.2 & & & & 2.55 & 6.07 & & & \\
\hline Yellow & 13 & 909.9 & 209.6 & & & & 0.23 & 0.44 & & & \\
\hline Immaculata & 9 & 784.7 & 222.1 & & & & 1.44 & 2.01 & & & \\
\hline
\end{tabular}

aBased on Kruskall-Wallis rank sum test statistic. 
Very low frequencies of any morph would render it susceptible to within-population extinction by demographic stochasticity (Calsbeek et al, 2002). Y-linkage of morph-determining alleles would exacerbate this process by reducing the effective population size of these alleles. This is a plausible explanation for the absence of red males from some populations, as we found no evidence of systematic geographic variation in morph frequencies among our study sites. There may, however, be geographic variation over a broader scale, as the red morph has not been reported from French Guiana despite extensive surveys (Keith et al, 2000; P-Y Le Bail, pers. comm.).

Male-beneficial, sexually antagonistic alleles are thought to preferentially accumulate on the Y-chromosome in male heterogametic species, because there they will not be expressed in females (Fisher, 1931; Rice, 1987). Despite strong theoretic (Rice, 1984, 1987) and experimental (Rice, 1992, 1994) evidence that sexually antagonistic genes should accumulate on Y-chromosomes, there are few compelling examples in natural systems. In $P$. parae, the relationship between male morph and sexual selection suggests that the genes underlying male morph may be sexually antagonistic. There is evidence from the guppy that genes determining attractive male colour patterns are associated with increased predation risk (Endler, 1983) and nonpredatory mortality (Brooks, 2000), which suggests that were such genes to be expressed in females they would confer a net decrement in fitness (ie they probably are sexually antagonistic). The Y-linkage of male colour morph genes in $P$. parae supports the hypothesis that such genes should be linked to the heterogametic chromosome.

$P$. parae exhibits one of the most complex sex-limited discrete polymorphisms known. Some closely related species are characterized by additional discrete polymorphisms, such as that found in P. picta, while the wellstudied guppy, $P$. reticulata, exhibits nearly continuous variation. Thus, this clade presents a unique opportunity to study the role of sexual selection in the maintenance of male colour polymorphism.

\section{Acknowledgements}

The Environmental Protection Agency of Guyana, Ministry of Agriculture of Guyana and Animal Husbandry and Fisheries of Suriname provided research and collecting permits. Indarjit Ramdass of the University of Guyana, Dyantie Naraine of the Centre for the Study of Biological Diversity in Guyana, Peter Kahtoo and Mr. Squires of the National Zoological Park, Godfrey Bourne of Ceiba Biological Centre, Cecil Persaud at Guyana Aquarium Traders and Jan Mol of the University of Suriname and Center for Agricultural Research of Suriname provided valuable support in South America. We thank Sahid Cantallops Peña, Michael Krützen and Orrin Clarke for assistance with field work in Guyana, the Smithsonian Institution for housing and logistical support in Guyana, Heather Alexander and Carlos Figueiredo for assistance in Suriname, Fred Kyba for assistance with preparation of Figure 1, and NR Liley for lending his aquarium facilities, sharing valuable field knowledge, and pioneering the study of poeciliid behaviour in Guyana. NSERC provided funding through a postdoctoral fellowship to AL, and operating grants to
FB and JNM Smith (University of British Columbia). Additional funding was provided by the University of New South Wales through the University Research Support Program, The Field Museum of Natural History and the National Geographic Society. We also thank Godfrey Bourne and Michael Krützen for comments on the manuscript.

\section{References}

Alonzo SH, Sinervo B (2001). Mate choice games, contextdependent good genes, and genetic cycles in the sideblotched lizard, Uta stansburiana. Behav Ecol Sociobiol 49: 176-186.

Angus RA (1989). A genetic overview of poeciliid fishes. In: Meffe GK, Snelson Jr FF (eds) Ecology and Evolution of Livebearing Fishes (Poeciliidae). Prentice-Hall: Englewood Cliffs, NJ. pp 51-68.

Bourne GR, Breden F, Allen TC (2003). Females prefer carotenoid males as mates in the pentamorphic livebearing fish, Poecilia parae. Natur Wissenschaften 90: 402-405.

Breden F, Ptacek M, Rashed M, Taphorn D, Augusto de Figueiredo C (1999). Molecular phylogeny of the live-bearing fish genus Poecilia (Cyprinodontiformes: Poeciliidae). Mol Phylogenet Evol 12: 95-104.

Brooks R (2000). Negative genetic correlation between male sexual attractiveness and survival. Nature 406: 67-70.

Calsbeek R, Alonzo SH, Zamudio K, Sinervo B (2002). Sexual selection and alternative mating behaviours generate demographic stochasticity in small populations. Proc Roy Soc London B 269: 157-164.

Clarke B (1962). Balanced polymorphism and the diversity of sympatric species. In: Nichols D (ed) Taxonomy and Geography. Systematics Association: Oxford. pp 47-70.

Constantz GD (1989). Reproductive biology of poeciliid fishes. In: Meffe GK, Snelson Jr. FF (eds) Ecology and Evolution of Livebearing Fishes (Poeciliidae). Prentice-Hall: Englewood Cliffs, NJ. pp 33-49.

Eigenmann CH (1894). Notes on some South American fishes. Ann N Y Acad Sci 7: 625-637.

Eigenmann $\mathrm{CH}$ (1909). Reports on the expedition to British Guiana of the Indiana University and the Carnegie Museum, 1908. Some new genera and species of fishes from British Guiana. Ann Carnegie Mus 6: 4-54

Endler JA (1978). A predator's view of animal color patterns. Evol Biol 11: 319-364.

Endler JA (1983). Natural and sexual selection on color patterns in poeciliid fishes. Env Biol Fish 9: 173-190.

Farr JA (1976). Social facilitation of male sexual behavior, intrasexual competition, and sexual selection in the guppy, Poecilia reticulata (Pisces: Poeciliidae). Evolution 30: 707-717.

Farr JA (1977). Male rarity or novelty, female choice behavior, and sexual selection in the guppy, Poecilia reticulata Peters (Pisces: Poeciliidae). Evolution 31: 162-168.

Fisher RA (1931). The evolution of dominance. Biol Rev 6: 345-368.

Godin, J-GJ, McDonough HE (2003). Predator preference for brightly colored males in the guppy: a viability cost for a sexually selected trait. Behav Ecol 14: 194-200.

Haskins CP, Haskins EF, McLaughlin JJA, Hewitt RE (1961). Polymorphism and population structure in Lebistes reticulatus, an ecological study. In: Blair, WF (ed) Vertebrate Speciation. University of Texas Press: Austin. pp 320-395.

Hughes KA, Du L, Rodd FH, Reznick DN (1999). Familiarity leads to female mate preference for novel males in the guppy, Poecilia reticulata. Anim Behav 58: 907-916.

Keith P, Le Bail P-Y, Planquette P (2000). Atlas des Poissons d'Eau Douce de Guyana, tome 2 fasicule 1. Muséum National d'Histoire Naturelle: Paris. 
Kondrashov AS, Kondrashov FA (1999). Interactions among quantitative traits in the course of sympatric speciation. Nature 400: 351-354.

Lande R (1981). Models of speciation by sexual selection on polygenic traits. Proc Natl Acad Sci USA 78: 3721-3725.

Lande R, Wilkinson GS (1999). Models of sex-ratio meiotic drive and sexual selection in stalk-eyed flies. Genet Res 74: 245-253.

Liley NR (1963). Reproductive Isolation in Some Sympatric Species of Fishes. DPhil Thesis, Oxford.

Liley NR (1966). Ethological isolating mechanisms in four sympatric species of poeciliid fishes. Behav Suppl 13: 1-197.

Lindholm AK, Breden F (2002). Sex chromosomes and sexual selection in poeciliid fishes. Am Nat 160: S214-S224.

Magurran A (1998). Population differentiation without speciation. Phil Trans Roy Soc London B 353: 275-286.

Reinhold K (1998). Sex linkage among genes controlling sexually selected traits. Behav Ecol Sociobiol 44: 1-7.

Ritchie MG, Phillips SDF (1998). The genetics of sexual isolation. In: Howard DJ, Berlocher SH (eds) Endless Forms. Oxford University Press: Oxford. pp 291-308.

Rice WR (1984). Sex chromosomes and the evolution of sexual dimorphism. Evolution 38: 735-742.
Rice WR (1987). Genetic hitchiking and the evolution of reduced genetic activity of the Y sex chromosome. Genetics 116: $161-167$.

Rice WR (1992). Sexually antagonistic genes: experimental evidence. Science 256: 1436-1439.

Rice WR (1994). Degeneration of a nonrecombining chromosome. Science 263: 230-232.

Rosen DE, Bailey RM (1963). The poeciliid fishes (Cyprinodontiformes), their structure, zoogeography, and systematics. Bull Am Mus Nat Hist 126: 3-126.

Shuster SM, Wade MJ (1991). Equal mating success among male reproductive strategies in a marine isopod. Nature 350: 608-610.

Sokal RR, Rohlf FJ (1969). Biometry. Freeman: San Francisco.

Sinervo B (2001). Runaway social games, genetic cycles driven by alternative male and female strategies, and the origin of morphs. Genetica 112-113: 417-434.

Sinervo B, Svensson E (2002). Correlational selection and the evolution of genomic architecture. Heredity 89: 329-338.

Winemiller KO, Leslie M, Roche R (1990). Phenotypic variation in male guppies from natural inland populations: an additional test of Haskins' sexual selection/predation hypothesis. Environ Biol Fish 29: 179-191. 